Check for updates

Cite this: RSC Adv., 2019, 9, 11558

\title{
A clean and effective potassium hydroxide pretreatment of corncob residue for the enhancement of enzymatic hydrolysis at high solids loading $\dagger$
}

\author{
Xuewen Chi, (DD ab Chao Liu, (D) ${ }^{\mathrm{b}}$ Yan-Hong Bi, ${ }^{\mathrm{a}}$ Guang Yu, ${ }^{\mathrm{b}}$ Yuedong Zhang, ${ }^{\mathrm{b}}$ \\ Zhaoyu Wang, ${ }^{* a}$ Bin Li ${ }^{* b}$ and Qiu Cuib
}

Corncob residue (CCR) is an economic feedstock with enormous potential for the production of bioethanol. In this work, potassium hydroxide $(\mathrm{KOH})$ pretreatment of $\mathrm{CCR}$ was investigated under relatively mild conditions, and the effectiveness of $\mathrm{KOH}$ pretreatment was evaluated by enzymatic saccharification at high solid loading. Results showed that after $\mathrm{KOH}$ pretreatment $(16 \mathrm{wt} \% \mathrm{KOH}$ dosage

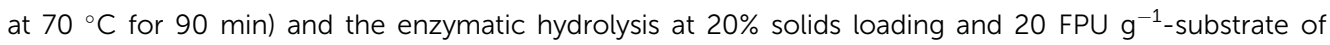
cellulase loading, the glucose yield could reach up to about $91 \%$, which was over $90 \%$ higher compared to the raw $\mathrm{CCR}$ without $\mathrm{KOH}$ pretreatment. Correspondingly, about $89 \%$ of lignin and $79 \%$ of extractives were removed after $\mathrm{KOH}$ pretreatment. In addition, the spent liquor of $\mathrm{KOH}$ pretreatment containing sylvite could be used as lignin-based fertilizer based on the concept of biorefinery. In this case, the entire process for the production of fermentable sugars was clean and sustainable, which is very vital for the conversion of lignocelluloses to bioenergy or chemicals.

Received 1st March 2019

Accepted 8th April 2019

DOI: 10.1039/c9ra01555h

rsc.li/rsc-advances
The global corn production was more than 900 million tons according to the report from the United States Department of Agriculture and approximately 40-50 million metric tons of corncobs could be collected. ${ }^{7}$ Due to its relatively high xylan content (about 25-30 wt\%), corncob can be used as a feedstock for xylose (mainly for the production of xylitol), xylooligosaccharides (used as food and feed additives), and furfural production. ${ }^{\mathbf{8}, 9}$ After the extraction of xylan, considerable amounts of corncob residue (CCR) were generated as industrial biomass waste. In China, over five million tons of CCR are generated annually, most of which are burned to recover heat and cause environmental problems. ${ }^{9}$ Hence, both researchers and engineers are looking for other solutions to better use CCR. It has been reported that CCR could be used for the production of high value carbon materials, ${ }^{\mathbf{1 0 , 1 1}}$ nanocellulose, ${ }^{12}$ levulinic acid by catalysis, ${ }^{\mathbf{1 3}}$ L-lactic acid by fermentation, ${ }^{\mathbf{1 4}}$ and also fermentable sugars by saccharification, ${ }^{\mathbf{1 5}}$ due to its unique properties, such as, small particle size, high porosity, and high cellulose content (>50 wt\%).

As for the production of fermentable sugars via enzymatic saccharification, pretreatment stage is highly required to break the natural recalcitrance (e.g., the presence of lignin, acetyl groups, extractives, and even ash, the high crystallinity of cellulose, the tight and dense arrangement of cell wall structure) of lignocelluloses, and the pretreatment methods that have been reported so far include physical, chemical, biological, and the combined methods. ${ }^{\mathbf{1 6}, 17}$ In sundry pretreatment
${ }^{a}$ School of Life Science and Food Engineering, Huaiyin Institute of Technology, Huai'an, Jiangsu, 223003, China. E-mail: biowzy@126.com; Fax: +86-517-83559982; Tel: +86-517-83559565

${ }^{b}$ CAS Key Laboratory of Biofuels, CAS Key Laboratory of Bio-based Material, Dalian National Laboratory of Clean Energy, Qingdao Institute of Bioenergy and Bioprocess Technology, Chinese Academy of Sciences, Qingdao, Shandong, 266101, China. E-mail: libin@qibebt.ac.cn; Fax: +86-532-80662724; Tel: +86-532-80662725

$\dagger$ Electronic supplementary information (ESI) available. See DOI: 10.1039/c9ra01555h 
methods, the chemical technique is mainly used to remove hemicellulose or lignin with acid, alkali, or organic solvents, among of which alkali-based pretreatment is one of the most studied technologies because (1) it can efficiently remove lignin, (2) obtain a high final total sugar yield (glucose + xylose), ${ }^{5}$ (3) generate less inhibitors compared to dilute acid pretreatment and hydrothermal pretreatment, ${ }^{18}$ and (4) it can be integrated with alkali-based pulp mill by partially utilizing the mature pulping equipment, the well-developed wastewater treatment and chemical recovery systems for the reduction of capital cost, based on the concept of integrated biorefinery. ${ }^{19}$

However, the mills that use agricultural waste (e.g., corncob, wheat straw) as the feedstock have a very smaller production scale compared to the large pulping plants which use wood chips, because agricultural waste has a quite limited collection radius due to its low density and high cost of transportation. ${ }^{4}$ In this case, the corresponding capital cost of alkali recovery system including the combustion of spent liquor and causticization (for the one with sodium hydroxide $(\mathrm{NaOH})$ ) will be very high. ${ }^{20}$ Although the recovery of sodium carbonate does not need causticization, sodium carbonate pretreatment has a lower effectiveness due to its weak basicity in comparison with $\mathrm{NaOH} .{ }^{21}$ Therefore, in the light of the properties of CCR (mainly contains cellulose and lignin) derived from xylose or furfural mills, more sustainable and effective pretreatment technology for delignification should be developed to be ready for the downstream enzymatic hydrolysis.

Potassium hydroxide $(\mathrm{KOH})$ can be used as an effective alkali reagent for pretreatment. ${ }^{22,23}$ In contrast with $\mathrm{NaOH}, \mathrm{KOH}$ could be a suitable solution to address the issue of high chemical recovery cost. Because the spent liquor of $\mathrm{KOH}$ pretreatment contains potassium, it could be used for the production of potash fertilizer to put nutrients back to soils for the clean and sustainable production. ${ }^{\mathbf{2 4 , 2 5}}$ On the other hand, KOH pretreatment could be implemented under relatively mild conditions due to the strong basicity of $\mathrm{KOH} .{ }^{26}$ Therefore, $\mathrm{KOH}$ pretreatment has a high potential feasibility.

Therefore, in the present work, the CCR originated from xylose mill was pretreated by $\mathrm{KOH}$ under the relatively mild conditions to efficiently remove lignin. The effectiveness of $\mathrm{KOH}$ pretreatment was evaluated by the enzymatic hydrolysis at high solid loading, which is very vital to reduce the capital and process cost for the downstream conversion of bioethanol or chemicals. ${ }^{27,28}$ Also, in order to intuitively observe the structure changes, the CCR samples before and after pretreatment were comprehensively characterized by scanning electron microscope (SEM), Fourier transform infrared spectroscopy (FTIR), and X-ray diffraction (XRD). In addition, the mass balance of $\mathrm{KOH}$ pretreatment and enzymatic hydrolysis at high solid loading was investigated as well. To our best knowledge, $\mathrm{KOH}$ pretreatment of CCR for the production of fermentable sugar and the matched enzymatic hydrolysis at high solids loading for the evaluation of the effectiveness of $\mathrm{KOH}$ pretreatment have not been reported in literature. The cost-effective and clean production of fermentable sugars from CCR (an industrial biomass waste) is of significant importance for the sustainable development of the local economy and society with the better and full utilization of lignocellulosic materials (e.g., agricultural wastes).

\section{Experimental}

\section{Materials}

Corncob residue (CCR) used in this work was gifted by Futaste Co., Ltd. (China), which use corncob as raw material for the manufacture of xylose and xylitol. The main steps for the production of xylose included dilute acid hydrolysis of corncob (to release xylose), hydrolyzate purification, concentration, and crystallization. ${ }^{29}$ The received CCR was placed in sealed bags and stored in refrigerator at $4{ }^{\circ} \mathrm{C}$ for use. All chemicals (e.g., $\mathrm{KOH}, \mathrm{H}_{2} \mathrm{SO}_{4}$ ) were purchased from Sinopharm Chemical Reagent Co. Ltd. and used directly without further purification. In addition, the cellulase enzyme was obtained by Qingdao Vland Biotech Inc. The activity of cellulase was $86 \mathrm{FPU} \mathrm{mL} \mathrm{m}^{-1}$, which was tested by the standard procedure, ${ }^{30}$ and the protein content of cellulase was $80 \mathrm{mg}$-protein per $\mathrm{mL}$, as determined by the standard Bradford method.

\section{KOH pretreatment of CCR}

The pretreatment of CCR was carried out in a cooking reactor (VRD-42SD-A China Pulp and Paper Research Institute, Beijing, China) equipped with four cooking tubes inside the reactor, and the volume of each tube was $1 \mathrm{~L}$. For each pretreatment experiment, $50 \mathrm{~g}$ CCR (oven dried basis) well mixed with different dosages of $\mathrm{KOH}$ was put into one cooking tube, and based on our previous work, ${ }^{4}$ the pretreatment was conducted with the solid to liquid ratio of $1: 10$ at $70{ }^{\circ} \mathrm{C}$ and $90{ }^{\circ} \mathrm{C}$ for $90 \mathrm{~min}$, respectively. During pretreatment, the cooking reactor was rotated with a speed of $1 \mathrm{rpm}$. Upon completion of $\mathrm{KOH}$ pretreatment, the mixed stock was taken out and separated into the solid of pretreated CCR and spent liquor though a filtration fabric bag with the mesh of 500. Then, the pretreated CCR was washed with de-ionized water until neutrality. After that, the washed samples were placed in locked plastic bags and stored at $4{ }^{\circ} \mathrm{C}$ for further tests.

\section{Enzymatic hydrolysis}

Enzymatic hydrolysis of CCR samples was carried out in $40 \mathrm{~mL}$ bottles in an air bath shaking incubator $(120 \mathrm{rpm})$ at $50{ }^{\circ} \mathrm{C}$ for $72 \mathrm{~h}$. The enzymatic hydrolysis were performed at solid loading of $2,5,10,15$, and $20 \%(\mathrm{w} / \mathrm{w})$, respectively, and the enzyme loading was $3,5,10,15$, and $20 \mathrm{FPU} \mathrm{g}^{-1}$-substrate, respectively (i.e., 3.4, 5.7, 11.2, 16.9, and $22.4 \mathrm{mg}$-protein per g-glucan, accordingly). Sodium citrate buffer $(0.1 \mathrm{M})$ was added to maintain the $\mathrm{pH}$ at 4.8 before enzymatic hydrolysis, and $200 \mu \mathrm{L}$ of $20 \mathrm{mg} \mathrm{mL}^{-1}$ sodium azide was added to prevent the growth of bacteria. Furthermore, hydrolyzate samples were taken after 12, 24,48 , and $72 \mathrm{~h}$ of hydrolysis to analyse the yield of glucose accordingly. Before analysis, hydrolyzate samples were centrifuged at $5000 \mathrm{rpm}$ for $5 \mathrm{~min}$, and then the supernatants were filtered through a membrane with pore size of $0.22 \mu \mathrm{m}$. After that, the concentration of glucose in hydrolyzate was determined by high-performance liquid chromatography (HPLC). 
Cellobiose was not detectable, because the cellulase cocktail contained some $\beta$-glucosidase.

Particularly, for the enzymatic hydrolysis with solid loading of $20 \%$, buffer solution was not used and the $\mathrm{pH}$ of the mixture was adjusted directly with $1 \mathrm{M} \mathrm{H}_{2} \mathrm{SO}_{4}$. Because of the difficulty of mass transfer in such high solid loading without flowable water, to achieve sufficient mixing between substrate and cellulase, the sealed glass bottles $(100 \mathrm{~mL})$ with substrates were fixed on a vertical rotary disc with the rotation speed of $10 \mathrm{rpm}$ (Fig. S1, $\dagger$ self-made incubator), and the saccharification was implemented with gravity blending at $50{ }^{\circ} \mathrm{C}$ in the first $24 \mathrm{~h}$ for initial liquefaction. After that, the sealed glass bottles were moved to the regular shaking incubator (SHA-C, Huangjie, China) for another $48 \mathrm{~h}$ hydrolysis. At last, the test of glucose concentration was conducted as mentioned above. The glucose yields were calculated based on the glucose mass in hydrolysates and the potentially available glucose in the CCR. ${ }^{31,32}$

\section{Chemical component analysis of CCR}

The chemical composition of the raw and pretreated CCR was determined by the typical two-stage acid hydrolysis approach in accordance with the National Renewable Energy Laboratory (NREL) protocol. ${ }^{33}$ The monosaccharides were tested by a HPLC (Model 1200, Agilent, USA) system equipped with a Bio-Rad Aminex HPX-87H column at $55{ }^{\circ} \mathrm{C}$. The $0.005 \mathrm{M} \mathrm{H}_{2} \mathrm{SO}_{4}$ was used as mobile phrase with a flow rate of $0.6 \mathrm{~mL} \mathrm{~min}^{-1}$. The effectiveness of $\mathrm{KOH}$ pretreatment and enzymatic hydrolysis was calculated using the following equations:

$$
\begin{aligned}
& R_{\text {solid }}(\%)=\left(M_{\text {pretreated biomass }} / M_{\text {original biomass }}\right) \times 100 \% \\
& R_{\text {glucan }}(\%)=\left(\left(R_{\text {solid }} \times C_{\text {glucan of pretreated biomass }}\right) /\right. \\
& \left.C_{\text {glucan of raw biomass }}\right) \times 100 \% \\
& D_{\text {lignin }}(\%)=\left(1-\left(R_{\text {solid }} \times C_{\text {lignin of pretreated biomass }}\right) /\right. \\
& \left.C_{\text {lignin of raw biomass }}\right) \times 100 \%
\end{aligned}
$$$$
Y_{\text {glucose }}(\%)=\left(M_{\text {glucose in Hydrolyzate }} \times 0.9 / M_{\text {glucan in raw biomass }}\right)
$$$$
\times 100 \%
$$

where, $R_{\text {solid }}$ and $R_{\text {glucan }}$ are the percentage of solid recovery and glucan recovery, respectively, after $\mathrm{KOH}$ pretreatment. $D_{\text {lignin }}$ is the delignification rate, and $Y_{\text {glucose }}$ is the glucose yield after enzymatic hydrolysis based on the corresponding glucose content in the raw CCR. $C$ is the content of the corresponding component in CCR (\%) and $M$ is the mass of the corresponding CCR $(\mathrm{g})$. All experiments in this work were performed at least in 4 times and the standard deviation was reported.

\section{Characterization of CCR before and after pretreatment}

The FTIR spectra of the untreated and pretreated CCR samples were detected on a FTIR spectrometer (Nicolet 6700, Thermo Fisher Scientific Inc., USA) though the standard $\mathrm{KBr}$ pellet method. The FTIR spectra was recorded with the wavenumber in the range of 4000 to $400 \mathrm{~cm}^{-1}$ with a resolution of $4 \mathrm{~cm}^{-1}$ and 32 scans per test. The crystalline structure of the untreated and pretreated CCR samples was determined by an XRD instrument
(D8 ADVANCE, Bruker Co., Germany) at $80 \mathrm{~mA}$ and $40 \mathrm{kV}$. The scanning angle was collected with the $2 \theta$ range from 5 to $65^{\circ}$, and the crystallinity index (CrI) was calculated on the basis of the Segal method. ${ }^{34}$ The SEM analysis of the CCR samples were carried out with a Hitachi S-4800 (Hitachi, Japan) at 3.0-8.0 kV in order to analyze the morphological structures of CCR before and after $\mathrm{KOH}$ pretreatment. Before scanning, samples were coated with platinum to improve the conductivity.

\section{Results and discussion}

\section{Chemical compositions of CCR after KOH pretreatment}

The chemical composition changes of CCR after pretreatment with varying $\mathrm{KOH}$ dosage at 70 and $90{ }^{\circ} \mathrm{C}$ are listed in Tables 1 and 2, respectively. As can be seen from Table 1, the untreated CCR mainly contained glucan (57\%) and lignin (21\%) with relatively low extractives, and the xylan content was only $2.7 \%$, which was due to the hydrolysis of hemicellulose during xylose production in xylose mill. Table 1 also presents that, with the increase of $\mathrm{KOH}$ dosage, the solid recovery after $\mathrm{KOH}$ pretreatment was declined obviously, which was mainly due to the efficient removal of lignin and extractives, thus leading to the increase of glucan content in the pretreated CCR. For instance, after pretreatment with $\mathrm{KOH}$ dosage of $16 \mathrm{wt} \%$ at $70{ }^{\circ} \mathrm{C}$, the solid recovery $\left(R_{\text {solid }}\right)$ was $66.4 \pm 0.3 \%$, the corresponding $D_{\text {lignin }}$ was $89.4 \pm 0.5 \%$, the extractives content decreased to $4.3 \pm$ $1.3 \%$, and the glucan content increased to $82.9 \pm 0.4 \%$. When $\mathrm{KOH}$ dosage was higher than $16 \mathrm{wt} \%$, the effectiveness of $\mathrm{KOH}$ pretreatment at the relatively lower temperature of $70{ }^{\circ} \mathrm{C}$ was basically steady.

However, in the case of $\mathrm{KOH}$ pretreatment at $90{ }^{\circ} \mathrm{C}$ with a higher $\mathrm{KOH}$ dosage (over $16 \mathrm{wt} \%$ ), despite a higher $D_{\text {lignin }}$ and glucan content could be obtained compared to the pretreatment at $70{ }^{\circ} \mathrm{C}$, the corresponding $R_{\text {solid }}$ kept reducing with the increment of $\mathrm{KOH}$ dosage (Table 2). For example, the $R_{\text {solid }}$ was lowered to about 54\% after the pretreatment with $\mathrm{KOH}$ dosage of $28 \mathrm{wt} \%$ at $90{ }^{\circ} \mathrm{C}$, which indicated the severe sugar loss due to the strong alkali condition. In fact, the corresponding glucan recovery was only about $85.7 \%$, which was clearly lower in comparison with the one $(96.6 \%)$ obtained after the pretreatment with $\mathrm{KOH}$ dosage of $16 \mathrm{wt} \%$ at $70{ }^{\circ} \mathrm{C}$. A higher glucan recovery after pretreatment could supply more available sugars for enzymatic hydrolysis, which was a prerequisite to gain a high final total sugar yield. ${ }^{35}$ Pretreatment with $\mathrm{KOH}$ dosage of $10 \mathrm{wt} \%$ could also achieve relative good delignification, but the enzymatic hydrolysis at high solids loading didn't perform well with this substrate, which will be discussed in later section.

\section{Enzymatic hydrolysis of pretreated CCR}

Enzymatic hydrolysis behaviors were generally considered to be a vital prototype for the evaluation of pretreatment efficiency. ${ }^{36}$ Shown in Fig. 1 is the effect of $\mathrm{KOH}$ dosage of pretreatment on glucose yield after enzymatic hydrolysis with a low solid loading (5\%) and a high enzyme loading (20 FPU g ${ }^{-1}$-substrate).

As can be seen from Fig. 1, for the CCR pretreated at $70{ }^{\circ} \mathrm{C}$, the glucose yield increased with the increase of $\mathrm{KOH}$ dosage. 
Table 1 The impact of $\mathrm{KOH}$ dosage on the effectiveness of pretreatment at $70{ }^{\circ} \mathrm{C}$

\begin{tabular}{|c|c|c|c|c|c|c|c|}
\hline $\mathrm{KOH}$ dose wt\% & $R_{\text {solid }}, \%$ & $\begin{array}{l}\text { Extractives } \\
\text { content, \% }\end{array}$ & Lignin content, \% & $D_{\text {lignin }}, \%$ & Glucan content, \% & $R_{\text {glucan }}, \%$ & Xylan content, \% \\
\hline$-^{a}$ & & $13.4 \pm 0.1$ & $20.5 \pm 0.6$ & & $57.0 \pm 1.4$ & & $2.7 \pm 0.1$ \\
\hline 7 & $74.7 \pm 0.1$ & $5.0 \pm 0.2$ & $10.5 \pm 0.3$ & $60.9 \pm 1.1$ & $75.4 \pm 0.1$ & $98.9 \pm 0.1$ & $3.8 \pm 0$ \\
\hline 10 & $70.8 \pm 0.2$ & $2.5 \pm 0.2$ & $5.5 \pm 0$ & $81.0 \pm 0.1$ & $79.2 \pm 0.6$ & $98.3 \pm 0.4$ & $3.3 \pm 0.6$ \\
\hline 13 & $66.7 \pm 0.3$ & $4.5 \pm 0.1$ & $5.3 \pm 0.2$ & $82.3 \pm 0.5$ & $81.9 \pm 0.4$ & $95.8 \pm 0.2$ & $3.1 \pm 0.7$ \\
\hline 16 & $66.4 \pm 0.3$ & $4.3 \pm 1.3$ & $3.0 \pm 0.2$ & $89.4 \pm 0.5$ & $82.9 \pm 0.4$ & $96.5 \pm 0.1$ & $2.2 \pm 0$ \\
\hline 19 & $65.7 \pm 0.2$ & $3.0 \pm 0.3$ & $3.2 \pm 0.3$ & $88.8 \pm 1.0$ & $84.6 \pm 0.4$ & $97.4 \pm 0.8$ & $2.1 \pm 0$ \\
\hline 22 & $65.0 \pm 0.2$ & $2.9 \pm 0.1$ & $3.6 \pm 0$ & $88.0 \pm 0$ & $85.4 \pm 0.4$ & $97.3 \pm 0.8$ & $2.1 \pm 0$ \\
\hline 25 & $64.6 \pm 0.1$ & $3.3 \pm 0$ & $3.7 \pm 0.2$ & $87.7 \pm 0.5$ & $87.0 \pm 1.0$ & $98.5 \pm 1.0$ & $2.1 \pm 0$ \\
\hline 28 & $64.8 \pm 0$ & $4.2 \pm 0.7$ & $3.5 \pm 0.3$ & $88.2 \pm 0.9$ & $85.2 \pm 0.1$ & $96.8 \pm 0.1$ & $2.3 \pm 0$ \\
\hline
\end{tabular}

Table 2 The impact of $\mathrm{KOH}$ dosage on the effectiveness of pretreatment at $90^{\circ} \mathrm{C}$

\begin{tabular}{|c|c|c|c|c|c|c|c|}
\hline $\mathrm{KOH}$ dose, wt\% & $R_{\text {solid }}, \%$ & $\begin{array}{l}\text { Extractives } \\
\text { content, \% }\end{array}$ & Lignin content, \% & $D_{\text {lignin }}, \%$ & Glucan content, \% & $R_{\text {glucan }}, \%$ & Xylan content, $\%$ \\
\hline$-^{a}$ & & $13.4 \pm 0.1$ & $20.5 \pm 0.6$ & & $57.0 \pm 1.4$ & & $2.7 \pm 0.1$ \\
\hline 7 & $70.8 \pm 0.1$ & $4.7 \pm 0$ & $9.9 \pm 0.3$ & $65.1 \pm 1.0$ & $77.8 \pm 0.7$ & $96.6 \pm 0.9$ & $3.6 \pm 0$ \\
\hline 10 & $66.9 \pm 0$ & $6.9 \pm 0$ & $5.0 \pm 0.2$ & $83.0 \pm 0.5$ & $79.7 \pm 0.2$ & $93.5 \pm 0.3$ & $1.8 \pm 0$ \\
\hline 13 & $62.1 \pm 0.6$ & $5.0 \pm 0.5$ & $4.1 \pm 0.3$ & $87.0 \pm 1.0$ & $85.9 \pm 0.1$ & $93.5 \pm 0.8$ & $1.9 \pm 0.3$ \\
\hline 16 & $61.8 \pm 0.1$ & $0.7 \pm 0.1$ & $0.8 \pm 0.2$ & $96.1 \pm 0.4$ & $87.5 \pm 0.1$ & $95.9 \pm 0.5$ & $1.5 \pm 0.1$ \\
\hline 19 & $59.6 \pm 0.1$ & $2.4 \pm 0.2$ & $1.5 \pm 0.2$ & $95.0 \pm 0.5$ & $88.8 \pm 0.2$ & $92.4 \pm 1.6$ & $1.4 \pm 0$ \\
\hline 22 & $57.0 \pm 0.4$ & $3.0 \pm 0.1$ & $1.3 \pm 0.2$ & $96.4 \pm 0.4$ & $91.5 \pm 0.3$ & $91.5 \pm 0.3$ & $1.5 \pm 0.1$ \\
\hline 25 & $56.3 \pm 0.1$ & $2.8 \pm 0.2$ & $1.4 \pm 0.2$ & $96.2 \pm 0.5$ & $92.1 \pm 0.6$ & $91.0 \pm 0.8$ & $2.0 \pm 0$ \\
\hline 28 & $54.4 \pm 0$ & $4.4 \pm 0$ & $1.4 \pm 0.2$ & $96.3 \pm 0.4$ & $89.8 \pm 1.4$ & $85.7 \pm 1.2$ & $1.2 \pm 0.1$ \\
\hline
\end{tabular}

When the $\mathrm{KOH}$ dosage was $7 \%$, the glucose yield was approximately $62 \%$. When the $\mathrm{KOH}$ dosage was $13 \mathrm{wt} \%$, the maximum glucose yield reached to about $98 \%$, which was 2 times higher compared to the raw CCR (48\%). The obvious improvement of glucose yield was mainly due to the efficient removal of lignin and extractives ${ }^{35}$ (Table 1), leading to the near complete releasing of glucose from the pretreated CCR during saccharification. Also, the glucose yield was basically steady when $\mathrm{KOH}$

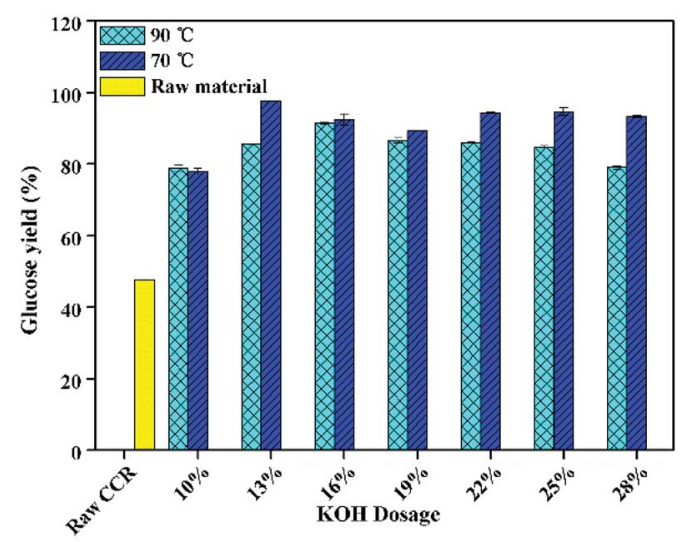

Fig. 1 The effect of $\mathrm{KOH}$ dosage on glucose yield after enzymolysis at a low solid loading of 5\% (enzymatic hydrolysis conditions: 20 FPU cellulase per g-substrate at $50{ }^{\circ} \mathrm{C}$ for $72 \mathrm{~h}$ ). dosage was over $13 \mathrm{wt} \%$, which was due to the fact that the corresponding $R_{\text {solid }}$ and glucan content in the pretreated CCR were relatively the same (Table 1 ). However, for the CCR pretreated at $90{ }^{\circ} \mathrm{C}$, the glucose yield showed a slightly declining trend with the increasing of $\mathrm{KOH}$ dosage when $\mathrm{KOH}$ dosage was higher than $16 \mathrm{wt} \%$, and the corresponding glucose yield with the pretreatment at $90{ }^{\circ} \mathrm{C}$ was relatively lower compared to the one with the pretreatment at $70{ }^{\circ} \mathrm{C}$. This phenomenon could be due to the loss of digestible glucan under severer pretreatment conditions.

Fig. 2 shows the effect of $\mathrm{KOH}$ dosage of pretreatment on glucose yield after enzymatic hydrolysis with a high solid loading (15\%) and a low enzyme loading (5 FPU g ${ }^{-1}$-substrate). It was found that, the glucose yield of raw CCR was the same either with low enzyme loading or with the high enzyme loading. However, as shown in Fig. 2, the glucose yield for the pretreated CCR with $\mathrm{KOH}$ dosage of $10 \mathrm{wt} \%$ was not improved after pretreatment. It is worth noting that the lignin content of the sample treated with $10 \mathrm{wt} \% \mathrm{KOH}$ was $5 \%$, which was higher than the ones (0.8-4.1 wt\%) with higher $\mathrm{KOH}$ dosage. Thus, a lower lignin content might be the key influential factor for achieving high glucose yield at high solid loading. Also, the glucose yield at solid loading of $15 \%$ was lower compared to the one at a lower solid loading (Fig. 1). These results were due to the fact that the mass transfer was hindered during saccharification at the high solid loading. ${ }^{15}$ Fig. 2 also presents that the 


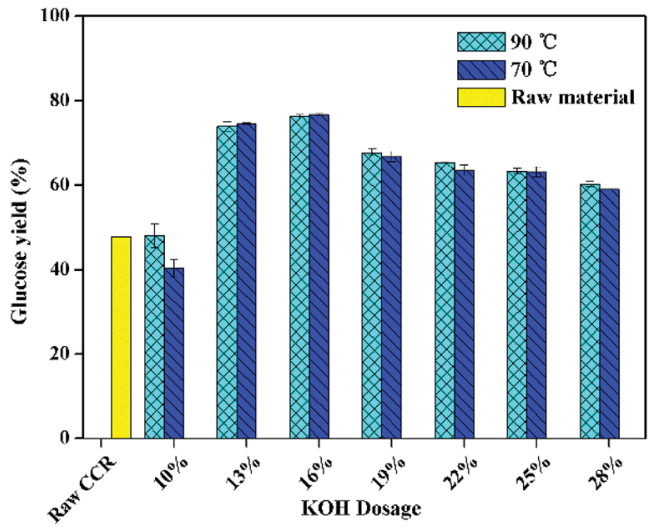

Fig. 2 The effect of $\mathrm{KOH}$ dosage on the glucose yield of enzymatic hydrolysis at $15 \%$ solid loading (enzymatic hydrolysis conditions: 5 FPU cellulase per $\mathrm{g}$-substrate at $50^{\circ} \mathrm{C}$ for $72 \mathrm{~h}$ ).

glucose yield with the pretreatment at $70{ }^{\circ} \mathrm{C}$ was systematically similar to the one with the pretreatment at $90{ }^{\circ} \mathrm{C}$, and the highest glucose yield was about $77 \%$ for the pretreated CCR with $\mathrm{KOH}$ dosage of $16 \mathrm{wt} \%$. Thus, to save energy consumption, the relatively lower temperature of $70{ }^{\circ} \mathrm{C}$ was suitable for $\mathrm{KOH}$ pretreatment of CCR.

For the following enzymatic hydrolysis, the used substrate was the pretreated CCR with $\mathrm{KOH}$ dosage of $16 \mathrm{wt} \%$ at $70{ }^{\circ} \mathrm{C}$ for $90 \mathrm{~min}$. The impact of solid loading on glucose yield of enzymatic hydrolysis is displayed in Fig. 3 . As can be seen, $97 \%$ of glucose yield could be obtained after enzymatic hydrolysis at the solid loading of $2 \%$, indicating that the $\mathrm{KOH}$ pretreated CCR had a quite higher digestibility with a very low cellulase loading

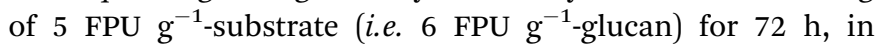
comparison with the CCR pretreated with deep eutectic solvents and enzymatic saccharification with $20 \mathrm{FPU} \mathrm{g}^{-1}$-substrate of cellulase. ${ }^{36}$ This glucose yield $(97 \%)$ was also clearly higher compared to the reported value of $83.7 \%$ for furfural residue with formic acid pretreatment combined alkaline hydrogen

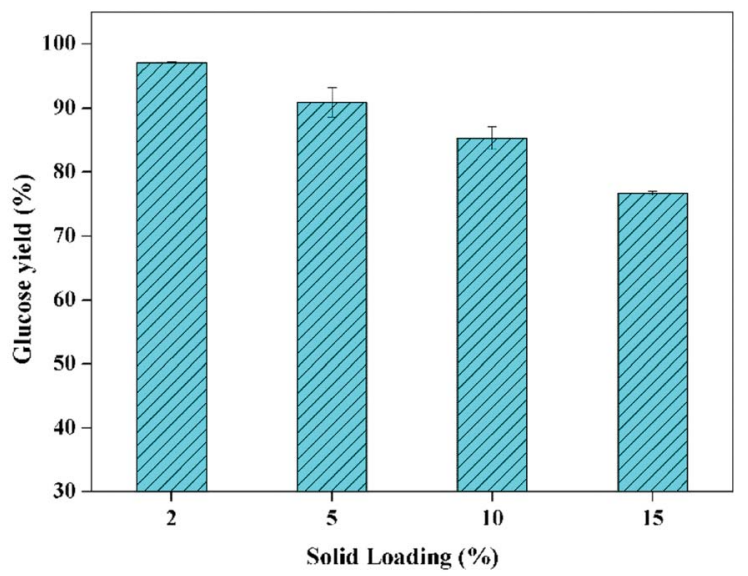

Fig. 3 The impact of solid loading on glucose yield of enzymatic hydrolysis (CCR pretreated with $16 \mathrm{wt} \%$ of $\mathrm{KOH}$ at $70{ }^{\circ} \mathrm{C}$ for $90 \mathrm{~min}$; enzyme loading of $5 \mathrm{FPU} \mathrm{g}{ }^{-1}$-substrate at $50^{\circ} \mathrm{C}$ for $72 \mathrm{~h}$ ). peroxide post-treatment and enzymatic hydrolysis with 7 FPU $\mathrm{g}^{-1}$-cellulose for $96 \mathrm{~h}^{37}$ Again, this high digestibility of pretreated CCR was mainly due to the sufficient removal of lignin and extractives. In addition, Fig. 3 also shows that, the glucose yield was gradually reduced with the increase of solid loading of saccharification, which was due to the increase of mass transfer limitation and product inhibition. ${ }^{15}$

However, it has been realized that enzymatic hydrolysis conducted at high-solids loadings $(\geq 15 \%, \mathrm{w} / \mathrm{w})$ is of significant importance for the increase of sugar concentration as well as the reduction of capital and process cost for the production of bioethanol. ${ }^{27}$ Therefore, enzymatic hydrolysis at solid loading of $15 \%$ should be investigated in detail. The glucose yield as the function of enzymatic hydrolysis time with different enzyme loadings is exhibited in Fig. 4, which presents that the glucose yield was up to $71 \%$ after enzymatic hydrolysis with the cellulase loading of $3 \mathrm{FPU} \mathrm{g}^{-1}$-substrate for $72 \mathrm{~h}$. Also, the enzymatic hydrolysis efficiency in the first 12 hours could be apparently enhanced when the enzyme loading was $10 \mathrm{FPU} \mathrm{g}^{-1}$-substrate (i.e. $12 \mathrm{FPU}^{-1}$-glucan), and the glucose yield could reach to about $85 \%$ after saccharification for $48 \mathrm{~h}$, which was obviously higher compared to the sulfite pretreated CCR $(81.2 \%)$ with the enzymatic hydrolysis at $2.5 \%$ of solid loading, $12 \mathrm{FPU} \mathrm{g}^{-1}$ -

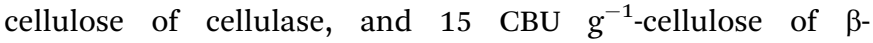
glucosidase. $^{38}$

In addition, a higher sugar concentration could be obtained after the enzymatic hydrolysis at higher solid loading, and theoretically higher sugar concentration could yield a higher ethanol concentration after fermentation, which could reduce the energy consumption and process cost of distillation..$^{39}$ It was reported that the downstream distillation could be economically feasible only with the ethanol concentration no less than $4 \%$, which meant that the corresponding solid loading of enzymatic hydrolysis should be no less than $20 \%$, generally. ${ }^{23,31}$ Therefore, the enzymatic hydrolysis at $20 \%$ of solid loading was further studied. To overcome the mass transfer limitation under such high solid loading, a two-step enzymatic hydrolysis

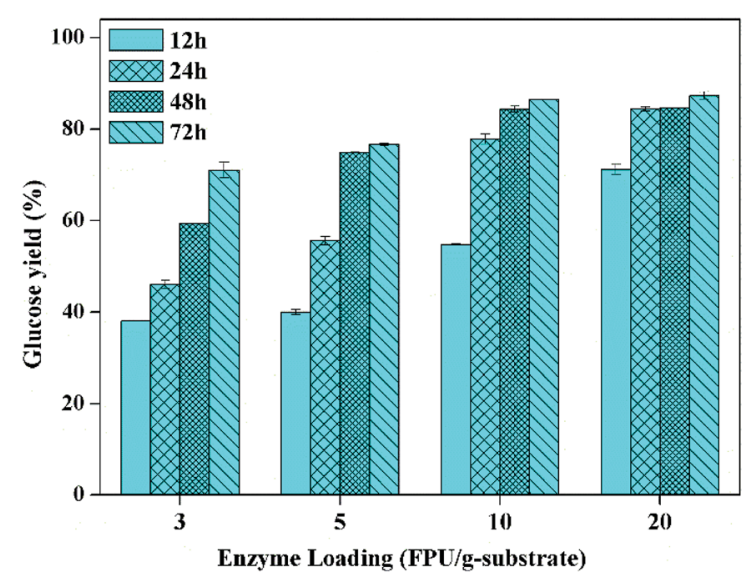

Fig. 4 Glucose yield as the function of enzymatic hydrolysis time with different enzyme loading (CCR pretreated with $16 \mathrm{wt} \%$ of $\mathrm{KOH}$ at $70^{\circ} \mathrm{C}$ for $90 \mathrm{~min}$; enzymatic hydrolysis solid loading of $15 \%$ at $50{ }^{\circ} \mathrm{C}$ ). 
was conducted. The first step for initial liquefaction was implemented with gravity blending, and the second step for complete saccharification was carried out with the regular mixing of shaking in incubator, as described in the experimental section. The impact of enzyme loading on glucose yield of high solid loading enzymatic hydrolysis (20\%) is given in Fig. 5, which exhibits that the glucose yield increased with the increase of enzyme loading, and the glucose yield could be boosted to 78 and $91 \%$ with the enzyme loading of 15 and 20 FPU $\mathrm{g}^{-1}$ substrate, respectively. To lower the enzyme loading at high solid loading enzymatic hydrolysis, sufficient pre-mixing during the initial liquefaction and fed-batch operation could be doable. ${ }^{15,27}$ The inhibition of enzymes by sugars is the other major influence factor impacting the enzymatic hydrolysis, and it could be reduced by timely separation of sugars. ${ }^{40}$

\section{Characterization of pretreated CCR}

To investigate the extent of the structure changes of CCR before and after $\mathrm{KOH}$ pretreatment, the FTIR, XRD, and SEM analyses were carried out. FTIR spectra and chemical band assignments of CCR are shown in supplementary Fig. S2 and Table S1, $\dagger$ respectively. The broad bands at around 3430 and $2900 \mathrm{~cm}^{-1}$ were attributed to the stretching of $-\mathrm{OH}$ and $\mathrm{C}-\mathrm{H}$ groups (of the aliphatic moieties in cellulose and lignin), respectively, ${ }^{\mathbf{1 1}}$ and the peak at $1640 \mathrm{~cm}^{-1}$ was due to the $\mathrm{O}-\mathrm{H}$ bending vibration of absorbed water. The bands at $1715 \mathrm{~cm}^{-1}$ was related to the $\mathrm{C}=\mathrm{O}$ stretching in lignin, the peaks at 1600 and $1510 \mathrm{~cm}^{-1}$ were associated with the aromatic skeletal vibration of lignin, the peak at $1261 \mathrm{~cm}^{-1}$ was assigned to the $\mathrm{C}-\mathrm{O}$ stretching in esters of lignin or the ester links between lignin and carbohydrates, ${ }^{35}$ and the band at $832 \mathrm{~cm}^{-1}$ was due to the $\mathrm{CH}$ out-of-plane deformation of benzenes in lignin. ${ }^{42}$ The intensity of these bands was clearly reduced (Fig. S2†), which was due to the efficient removal of lignin. Correspondingly, the intensity of the peaks at $1314 \mathrm{~cm}^{-1}\left(\mathrm{CH}_{2}\right.$ rocking vibration at $\left.\mathrm{C} 6\right), 898 \mathrm{~cm}^{-1}(\mathrm{C}-$ $\mathrm{O}-\mathrm{C}$ stretching at the $\beta$-(1-4)-glycosidic linkages), and $662 \mathrm{~cm}^{-1}$ $(\mathrm{C}-\mathrm{OH} \text { out-of-plane bending })^{43}$ were relatively increased after

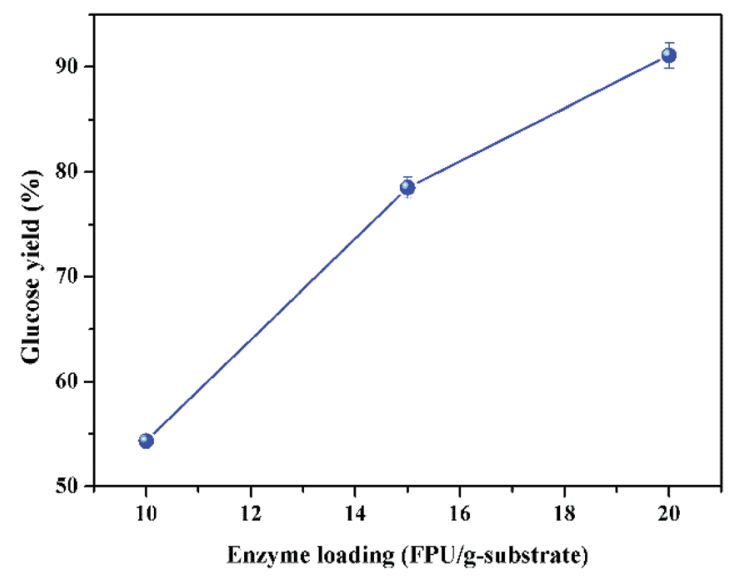

Fig. 5 Impact of enzyme loading on glucose yield after enzymolysis at the solid loading of $20 \%$ (CCR pretreated with $16 \mathrm{wt} \%$ of $\mathrm{KOH}$ at $70{ }^{\circ} \mathrm{C}$ for $90 \mathrm{~min}$; enzymatic hydrolysis at $50{ }^{\circ} \mathrm{C}$ for $72 \mathrm{~h}$ ).
$\mathrm{KOH}$ pretreatment because of the increase of glucan proportion in the pretreated CCR, and this result was in line with the component analysis (Tables 1 and 2).

FTIR analysis can also be used to calculate the cellulose crystallinity, and the total crystallinity index (TCI) and lateral order index (LOI) were calculated by the FTIR absorbance ratios of A1372/A2900 and A1430/A897, respectively. ${ }^{\mathbf{4 4 , 4 5}}$ However, CrI based on XRD was used to calculate the crystallinity index of CCR samples including lignin and extractives, in addition to the non-crystalline cellulose. As can be seen from Table 3, the CrI of pretreated CCR was increased and the CrI of the pretreated CCR with $16 \mathrm{wt} \% \mathrm{KOH}$ was up to $61.3 \%$, which was about $18 \%$ higher in comparison with the raw CCR. Correspondingly, the intensity of 101 and 002 peaks of pretreated CCR was relatively increased (Fig. S3 in ESI $\dagger$ ). These results were due to the removal of amorphous lignin and extractives after pretreatment. ${ }^{35}$ In contrast, the TCI and LOI of cellulose were obviously reduced after $\mathrm{KOH}$ pretreatment, which was associate with the destruction of the crystalline region of cellulose. Similar results were also reported previously.,46

In addition, pretreatment could modify the morphology of CCR as well, and the changes before and after $\mathrm{KOH}$ pretreatment are evidenced in Fig. 6. It was observed that the raw CCR (Fig. 6a) displayed a compact and rough surface structure due to the cover of lignin and extractives on the surface of cellulose fiber, which could hinder the accessibility of cellulose to enzyme. Yet, the surface of pretreated CCR became relatively smoother (Fig. 6b) because of the removal of lignin and extractives as listed in Tables 1 and 2. With the increase of $\mathrm{KOH}$ dosage, more lignin could be extracted. As a consequence, a large amount of pores were generated (Fig. 6c), which was beneficial to the amelioration of downstream enzymatic saccharification. ${ }^{5}$

\section{Mass balance of KOH pretreatment and enzymolysis}

The overall process and mass balance of $\mathrm{KOH}$ pretreatment and enzymatic hydrolysis of CCR is exhibited in Fig. 7. As can be seen, $1 \mathrm{~kg}$ CCR derived from a xylose mill was pretreated with $\mathrm{KOH}$ at relatively mild conditions $(16 \mathrm{wt} \%$ of $\mathrm{KOH}$ dosage at $70{ }^{\circ} \mathrm{C}$ for $90 \mathrm{~min}$ ). After pretreatment, about $89 \%$ of lignin and $79 \%$ of extractives were efficiently removed, and only about $3.4 \%$ of cellulose (i.e. glucan) was lost by degradation, leading to a quite high digestibility of the pretreated CCR. Subsequently, the pretreated CCR was subjected to enzymatic hydrolysis at a high solid loading of $20 \%$ with the cellulase loading of $20 \mathrm{FPU}$ $\mathrm{g}^{-1}$-substrate, and $578 \mathrm{~g}$ glucose $\left(217 \mathrm{~g} \mathrm{~L}^{-1}\right)$ and $13.6 \mathrm{~g}$ xylose could be released after saccharification for $72 \mathrm{~h}$ (further prolonging saccharification time only slightly increase the sugar

Table 3 Crystallinity of CCR measured by FTIR and XRD

\begin{tabular}{lccc}
\hline Samples & TCI & LOI & CrI (\%) \\
\hline Raw CCR & 1.12 & 3.95 & 51.8 \\
Pretreated CCR with 10 wt\% KOH & 1.09 & 2.99 & 58.7 \\
Pretreated CCR with 16 wt\% KOH & 1.03 & 2.87 & 61.3
\end{tabular}




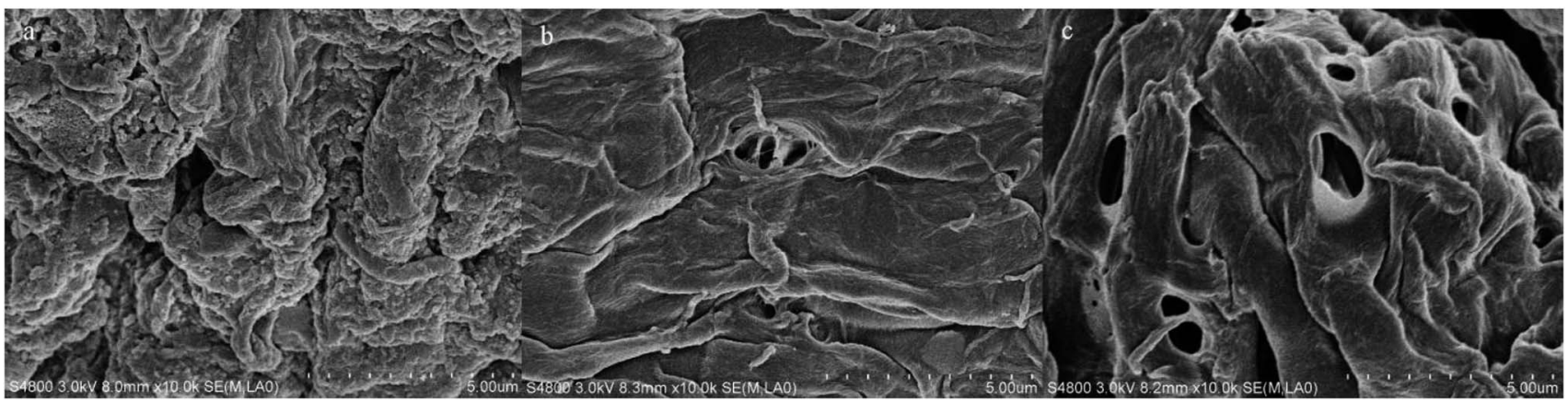

Fig. 6 SEM images of CCR samples before and after KOH pretreatment ((a) raw CCR; (b) pretreated CCR with 10 wt\% KOH; (c) pretreated CCR with 16 wt\% $\mathrm{KOH})$.

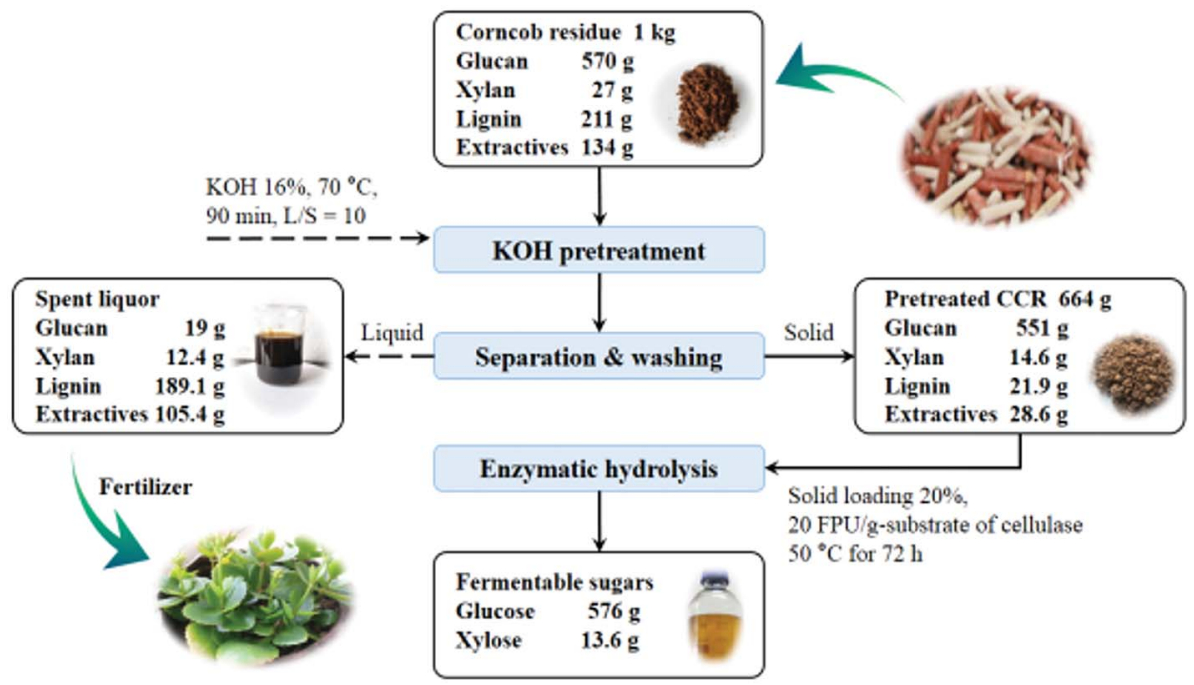

Fig. 7 Overall mass balance of $\mathrm{KOH}$ pretreatment and enzymatic hydrolysis of $\mathrm{CCR}$.

yield (less than $0.5 \%$ )). The corresponding glucose yield was $91 \%$ based on the glucose content of raw CCR, and that was over $90 \%$ higher compared to the raw CCR without $\mathrm{KOH}$ pretreatment. Also, according to the results obtained, if the cellulase loading was fixed at $5 \mathrm{PFU} \mathrm{g}^{-1}$-substrate (i.e. $6 \mathrm{FPU} \mathrm{g}^{-1}$-glucan) to lower the cost of saccharification, the solid loading of enzymatic hydrolysis should be reduced to $15 \%$ to reach a relatively high glucose yield of $77 \%$, and correspondingly, $488 \mathrm{~g}$ glucose (129 $\mathrm{g} \mathrm{L}^{-1}$ ) could be obtained from $1 \mathrm{~kg}$ raw CCR after $\mathrm{KOH}$ pretreatment and enzymatic saccharification.

In addition, under the conditions of $\mathrm{KOH}$ pretreatment $(16$ wt $\%$ of $\mathrm{KOH}$ dosage at $70^{\circ} \mathrm{C}$ for $90 \mathrm{~min}$ ), $0.16 \mathrm{t} \mathrm{KOH}$ was needed to treat $1 \mathrm{t}$ raw $\mathrm{CCR}$, and the generated spent liquor of $\mathrm{KOH}$ pretreatment contained $134 \mathrm{~kg} \mathrm{~K}$ (equivalent to $\mathrm{K}_{2} \mathrm{O}$ ), which could be used for producing lignin-based fertilizer based on the concept of the integrated biorefinery. ${ }^{25,47}$ In this case, the whole process of $\mathrm{KOH}$ pretreatment under the relatively mild conditions could be more sustainable and economically feasible, which could be potentially applied to the conversion of lignocelluloses to bioenergy or chemicals.

\section{Conclusion}

In this work, corncob residue (CCR) was pretreated by $\mathrm{KOH}$ under relatively mild conditions, and the effectiveness of $\mathrm{KOH}$ pretreatment was evaluated by enzymatic hydrolysis at high solids loading. It was found that $\mathrm{KOH}$ pretreatment efficiently removed lignin and extractives, which could effectively improve the enzyme accessibility of substrates, thus apparently improving the efficiency of the downstream enzymatic hydrolysis. About $91 \%$ of glucose yield was obtained after $\mathrm{KOH}$ pretreatment ( $16 \mathrm{wt} \%$ of $\mathrm{KOH}$ dosage at $\left.70{ }^{\circ} \mathrm{C}\right)$ and the enzymatic hydrolysis at $20 \%$ of solid loading with $20 \mathrm{FPU} \mathrm{g}^{-1}$ substrate of cellulase loading. This glucose yield was over $90 \%$ higher compared to raw CCR without $\mathrm{KOH}$ pretreatment. In addition, the spent liquor of $\mathrm{KOH}$ pretreatment could be used as lignin-based fertilizer on the basis of the concept of biorefinery. In this case, the overall process for the production of fermentable sugar was clean and sustainable, which will be conducive to the protection of environment and the conversion of lignocelluloses to bioenergy or chemicals. 


\section{Conflicts of interest}

There are no conflicts to declare.

\section{Abbreviations}

$\begin{array}{ll}\text { CCR } & \text { Corncob residue } \\ \text { CrI } & \text { Crystallinity index } \\ \text { TCI } & \text { Total crystallinity index } \\ \text { LOI } & \text { Lateral order index }\end{array}$

\section{Acknowledgements}

The authors would like to thank the Natural Science Foundation of China (No. 31870568, No. 21676114, and No. 31700509), the Major Program of Shandong Province Natural Science Foundation (No. ZR2018ZB0208), Six Talent Peaks Project of Jiangsu Province (No. SWYY-011), as well as the "Transformational Technologies for Clean Energy and Demonstration”, Strategic Priority Research Program of the Chinese Academy of Sciences (No. XDA21060201).

\section{References}

1 L. R. Lynd, X. Liang, M. J. Biddy, A. Allee, H. Cai, T. Foust, M. E. Himmel, M. S. Laser, M. Wang and C. E. Wyman, Curr. Opin. Biotech., 2017, 45, 202-211.

2 B. Satari, K. Karimi and R. Kumar, Sustainable Energy Fuels, 2019, 3, 11-62.

3 R. Kumar, M. Tabatabaei, K. Karimi and I. Sárvári Horváth, Biofuel Res. J., 2016, 3, 347-356.

4 X. Xie, X. Feng, S. Chi, Y. Zhang, G. Yu, C. Liu, Z. Li, B. Li and H. Peng, Bioresource Technology Reports, 2018, 3, 169-176.

5 H. Xu, B. Li and X. Mu, Ind. Eng. Chem. Res., 2016, 55, 86918705.

6 F. Battista and D. Bolzonella, Biofuels, Bioprod. Biorefin., 2018, 12, 711-723.

7 W. H. Qu, Y. Y. Xu, A. H. Lu, X. Q. Zhang and W. C. Li, Bioresour. Technol., 2015, 189, 285-291.

8 Y. Zhang, X. Mu, H. Wang, B. Li and H. Peng, J. Agric. Food Chem., 2014, 62, 4661-4667.

9 C. Liu, B. Li, H. Du, D. Lv, Y. Zhang, G. Yu, X. Mu and H. Peng, Carbohydr. Polym., 2016, 151, 716-724.

10 F. Yue, J. Zhang, C. M. Pedersen, Y. Wang, T. Zhao, P. Wang, Y. Liu, G. Qian and Y. Qiao, ChemistrySelect, 2017, 2, 583590.

11 W. H. Qu, Y. Y. Xu, A. H. Lu, X. Q. Zhang and W. C. Li, Bioresour. Technol., 2015, 189, 285-291.

12 C. Liu, H. Du, L. Dong, X. Wang, Y. Zhang, G. Yu, B. Li, X. Mu, H. Peng and H. Liu, Ind. Eng. Chem. Res., 2017, 56, 8264-8273.

13 C. Wang, Q. Zhang, Y. Chen, X. Zhang and F. Xu, ACS Sustainable Chem. Eng., 2018, 6, 3154-3161.

14 X. Kong, B. Zhang, Y. Hua, Y. Zhu, W. Li, D. Wang and J. Hong, Bioresour. Technol., 2019, 273, 220-230.
15 J. Du, Y. Cao, G. Liu, J. Zhao, X. Li and Y. Qu, Bioresour. Technol., 2017, 229, 88-95.

16 J. S. Kim, Y. Y. Lee and T. H. Kim, Bioresour. Technol., 2016, 199, 42-48.

17 K. Karimi, M. Shafiei and R. Kumar, in Biofuel Technologies, 2013, ch. 3, pp. 53-96, DOI: 10.1007/978-3-642-34519-7_3.

18 S. Sun, X. Cao, S. Sun, F. Xu, X. Song, R. C. Sun and G. L. Jones, Biotechnol. Biofuels, 2014, 7, 116.

19 A. von Schenck, N. Berglin and J. Uusitalo, Appl. Energy, 2013, 102, 229-240.

20 W. Gong, C. Liu, X. Mu, H. Du, D. Lv, B. Li and S. Han, ACS Sustainable Chem. Eng., 2015, 3, 3477-3485.

21 W. Geng, T. Huang, Y. Jin, J. Song, H. M. Chang and H. Jameel, Bioresour. Technol., 2014, 161, 63-68.

22 S. Sun, X. Cao, S. Sun, F. Xu, X. Song, R. C. Sun and G. L. Jones, Biotechnol. Biofuels, 2014, 7, 116.

23 X. Liu, S. M. Zicari, G. Liu, Y. Li and R. Zhang, Bioresour. Technol., 2015, 185, 150-157.

24 M. S. Jahan, F. Haris, M. M. Rahman, P. R. Samaddar and S. Sutradhar, Bioresour. Technol., 2016, 219, 445-450.

25 M. S. Jahana and Z. He, J. Bioresour. Bioprod., 2018, 3, 1-2.

26 E. Z. Hoşgün, D. Berikten, M. Kıvanç and B. Bozan, Fuel, 2017, 196, 280-287.

27 A. A. Modenbach and S. E. Nokes, Biomass Bioenergy, 2013, 56, 526-544.

28 T. Y. Nguyen, C. M. Cai, R. Kumar and C. E. Wyman, Proc. Natl. Acad. Sci. U. S. A., 2017, 114, 11673-11678.

29 Y. Chen, B. Dong, W. Qin and D. Xiao, Bioresour. Technol., 2010, 101, 7005-7010.

30 T. K. Ghose, Pure Appl. Chem., 1987, 59, 257-268.

31 T. Y. Nguyen, C. M. Cai, O. Osman, R. Kumar and C. E. Wyman, Green Chem., 2016, 18, 1581-1589.

32 A. Mohagheghi, M. Tucker, K. Grohmann and C. Wyman, Appl. Biochem. Biotechnol., 1992, 33, 67-81.

33 A. Sluiter, B. Hames, R. Ruiz, C. Scarlata, J. Sluiter, D. Templeton and D. Crocker, 2008.

34 L. Segal, J. J. Creely, A. E. Martin and C. M. Conrad, Text. Res. J., 1959, 29, 786-794.

35 H. Xu, G. Yu, X. Mu, C. Zhang, P. DeRoussel, C. Liu, B. Li and H. Wang, Ind. Crops Prod., 2015, 76, 638-646.

36 Z. Guo, Z. Ling, C. Wang, X. Zhang and F. Xu, Bioresour. Technol., 2018, 265, 334-339.

37 C.-Z. Chen, M.-F. Li, Y.-Y. Wu and R.-C. Sun, Ind. Eng. Chem. Res., 2014, 53, 12935-12942.

38 L. Bu, Y. Xing, H. Yu, Y. Gao and J. Jiang, Biotechnol. Biofuels, 2012, 5, 87.

39 C. E. Wyman, C. M. Cai and R. Kumar, in Energy from Organic Materials (Biomass), 2019, ch. 521, pp. 997-1022, DOI: 10.1007/978-1-4939-7813-7_521.

40 J. B. Kristensen, C. Felby and H. Jorgensen, Biotechnol. Biofuels, 2009, 2, 11.

41 Y. Tang, X. Shen, J. Zhang, D. Guo, F. Kong and N. Zhang, Carbohydr. Polym., 2015, 125, 360-366.

42 J. B. Lambert, H. F. Shurvell, D. A. Lighter and R. G. Cooks, Introduction to Organic Spectroscopy, Macmillan, NY, 1987, pp. 174-177. 
43 B. Li, W. Xu, D. Kronlund, A. Maattanen, J. Liu, J. H. Smatt, J. Peltonen, S. Willfor, X. Mu and C. Xu, Carbohydr. Polym., 2015, 133, 605-612.

44 M. L. Nelson and R. T. O. Connor, J. Appl. Polym. Sci., 1964, 8, 1325-1341.
45 R. T. O'Connor, E. F. DuPré and D. Mitcham, Text. Res. J., 1958, 28, 382-392.

46 H. Mou, B. Li and P. Fardim, Energy Fuels, 2014, 28, 42884293.

47 G. Wu, Y. Zhang, B. Yuan, C. Liu, G. Yu, C. Xie, B. Li and H. Peng, Cellulose, 2018, 26, 2087-2097. 